\title{
Spascupreel $\AA^{\circledR}$ for primary dysmenorrhoea
}

\author{
Volume 4 Issue 2 - 2016
}

\section{Background and motivation}

Dysmenorrhoea, a common gynaecological complaint, causes severe and disabling pain which reduces woman's quality of life including absenteeism from work place. Fifty to sixty percent of reproductive age women report pain during menstruation. ${ }^{1}$ Despite advances in the treatment of primary dysmenorrhoea, a study of 1,546 menstruating Canadian women in 2015 found that $60 \%$ were having the disorder. ${ }^{2}$ Sixty percent of the dysmenorrheic women were having severe or moderate pain. Fifty-one percent reported limitation of activities, and $17 \%$ reported absenteeism from school or work of those reporting pain, $13.5 \%$ suffer from a severe pain with a high impact on their normal life or job during days of the menstrual cycle. Primary dysmenorrhoea is a very common problem in young women. It is usually defined as cramping pain in the lower abdomen occurring at the onset of menstruation in the absence of any identifiable pelvic disease. The prevalence of primary dysmenorrhoea decreases with increasing age: prevalence is highest in the 20- to 24-year-old age group and decreases progressively thereafter. ${ }^{3}$

The primary dysmenorrhoea is distinguished from secondary dysmenorrhoea, which refers to painful menses resulting from pelvic pathology such as endometriosis. As such, agents that reduce prostaglandins, such as non-steroidal anti-inflammatory drugs (NSAIDs), and hormonal contraceptives, are used to treat dysmenorrhoea. The menstrual phase is the phase during which the lining of the uterus (endometrium) is shed as menstrual flow out of the cervix and vagina. Dysmenorrhoea is a menstrual condition characterized by severe and frequent menstrual cramps and pain associated with menstruation, Figure 1 illustrates the pre-and postmenstrual phases.

\section{Pathogenesis of dysmenorrhoea}

Increased prostaglandin synthesis and inflammatory processes during menstruation result in uterine contractions and vasoconstriction. This uterine hyper-contractility and ischemia lead to pain which is consistent with the time of maximal prostaglandin release into the menstrual fluid (vide infra).

Vasopressin also may play a role by increasing uterine contractility and causing ischemic pain as a result of vasoconstriction. Elevated vasopressin levels have been reported in women with primary dysmenorrhoea. ${ }^{4,5}$ Primary dysmenorrhoea occurs only during ovulatory cycles. ${ }^{6}$ Risk factors for dysmenorrhoea include null parity, heavy menstrual flow, smoking, and depression. Dysmenorrhoea is increased with smoking.

\section{Diagnose of primary dysmenorrhoeal}

The typical history of primary dysmenorrhoea and absence of any positive findings in the physical examination are key diagnostic features and there is no laboratory test for it. The diagnostic history includes the propinquity of the onset of primary dysmenorrhoea with menarche, the start of symptoms with the onset of menstrual flow, and the duration of menstrual cramping and its characteristic description.

\author{
Yousef Jasemian \\ Maricopa Integrated Health System, USA
}

Correspondence: Yousef Jasemian, Elizabeth Renee Prevette, ANP, Maricopa Integrated Health System, 260 I E. Roosevelt St., Phoenix,Arizona, Email yousef@jasemian.com

Received: July 10, 2016 | Published: August 08, 2016

The symptoms of primary dysmenorrhoea are usually most intense in the first 2 to 3 days of flow. The pains are suprapubic in location, but may also radiate to the thighs/inner thighs. Common symptoms in a high percentage of cases are cramps which are frequently accompanied by backache, nausea, vomiting, and diarrhoea. Other symptoms that may accompany cramping include dizziness, fatigue, headache, or a flu-like feeling.

To rule out secondary dysmenorrhoea the women with dysmenorrhoea should have a complete abdominal and pelvic examination. During the examination, the healthcare provider will observe and feel the size and shape of the vagina, cervix, utera, and ovaries. However, an internal pelvic examination may not be necessary in adolescent girls. In some women, pelvic ultrasound can be useful in determining if conditions such as uterine fibroids, adenomyosis, or endometriosis are present.

\section{Treatment approaches for dysmenorrhoea}

I. Nonsteroidal anti-inflammatory drugs (NSAIDs) as first-line therapy. ${ }^{7}$

II. Hormonal contraceptive such as oral combination contraceptive. ${ }^{8}$

III. Injectable depot medroxyprogesterone acetate

a. Depot medroxyprogesterone acetate (DMPA) which is a longacting reversible hormonal contraceptive birth control drug that is injected every three months. It is a progestin- only contraceptive. It is marketed under the brand name DepoProvera $^{9}$ (visited July 7th 2016).

IV. Levonorgestrel-releasing intrauterine system (IUD), ${ }^{10}$ (visited July 7th 2016).

a. These methods (1-4) reduce the amount and duration of menstrual flow, resulting in alleviation of menstrual symptoms such as pain. 
V. Danazol and gonadotropin-releasing hormone (GnRH) agonists can be used to suppress the menstrual cycle (these agents are associated with significant side effects and increased costs), ${ }^{11}$ (visited July 7th 2016).

VI. Locally applied heat which stimulate local vasodilation to reverse vasoconstriction caused by vasopressin release.

VII. Supplements (magnesium, fish oil, calcium, Vitamine B6, Vitamine A, E).

a. Vitamine A through a natural whole food source (e.g. cod liver oil) or beta-carotene (carrots). This will help to keep estrogen levels regulated.

b. Magnesium helps to relax smooth muscles. It has been shown to reduce menstrual cramps significantly.

VIII. Herbal remedies (e.g. Borage tea/extract, Evening Primrose Oil (EPO), Wild Yam, sweet fennel, krill oil)

a. Both Borage oil and Evening Primrose Oil are high in Omega-6 fatty acids. Omega- 6 can assist fertility by improving reproductive cell structure and decrease risk of inflammation. Borage and EPO tone the uterus ${ }^{12}$ (visited July 8th 2016).

b. Insufficient evidence on Krill oil's benefit for $\mathrm{PMS}^{13}$ (visited July 8th 2016).

c. Wild Yam works as relaxant on smooth muscle tissue, reducing muscle spasm of the uterus, fallopian tubes and ovaries, helping painful menstruation.

d. Sweet Fennel (Foeniculum vulgare, Foeniculum officinale, Anthum foeniculum) helps to regulate the menstrual cycle, may help reduce hormone fluctuation. It is also aids in reducing muscle spasm (Caution*: Do not use if you have epilepsy).

IX. Acupuncture and acupressure.

X. Transcutaneous electrical nerve stimulation (TENS).

Despite many case study's promising results with the use of methods 6-10, There are limited evidence to support that.

\section{Aims}

We investigated the analgesic efficacy of Spascupree ${ }^{\circledR}$ on primary dysmenorrhoea compared with $\operatorname{Advi}^{\circledR}$ (Ibuprofen). Spascupreel ${ }^{\circledR}$ is a homoeopathic medication for treating spasms. $\mathrm{Advi}^{\circledR}$ was used as a non-steroidal anti-inflammatory compound with good efficacy shown in a multicenter, randomized, double-blind, and crossover study. ${ }^{14}$ Spascupree $l^{\circledR}$ was chosen on the basis of the previous report on its efficacy, and good tolerability in German Research Study. ${ }^{15}$

\section{Medications in investigation}

A. Advi ${ }^{\circledR}$ Liquigels (Figure 2): Solubilized Ibuprofen equal to 200mg Ibuprofen (prostaglandin inhibitor)

i. Inactive ingredients: FD\&C green no. 3, gelatin, light mineral oil, pharmaceutical ink, polyethylene glycol, potassium hydroxide, purified water, sorbitans, sorbitol

ii. Risks/ adverse effects: Allergy, stomach bleeding, risk of heart attack or stroke in long term use.

B. Spascupreel ${ }^{\circledR}$ (Homeopathic preparation Figure 3): $300 \mathrm{mg}$ sublingual tablets (spasms reliever in the organs of the smooth and striated musculature). One tablet contains: Citrullus colocynthis, Ammonium bromatum, Atropium sulfuricum, Veratrum Album, Magnesium phosphoricum, Gelsemium sempervirens, Passiflora incarnata, Agaricus, Chamomilla recutita, Cuprum sulfuricum, Aconitum napellus.

i. Risks/ adverse effects: No report.

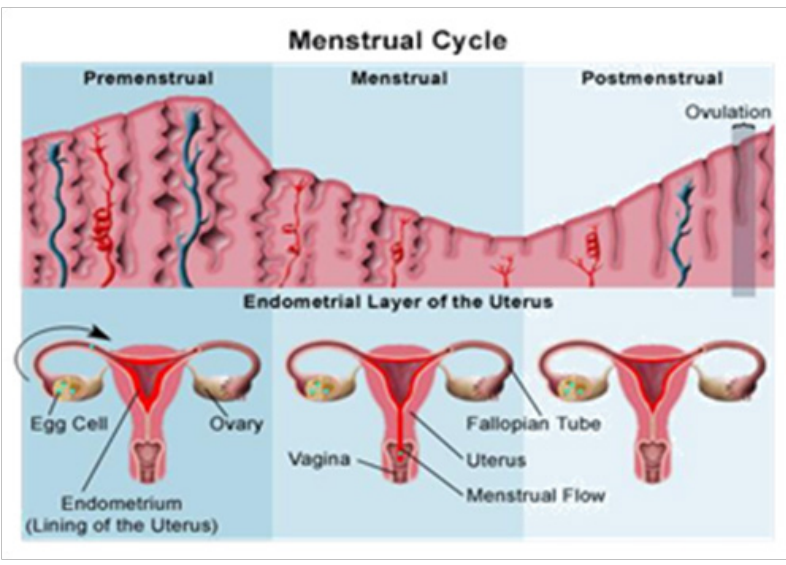

Figure I menstrual cycle (pre-and postmenstrual phases).

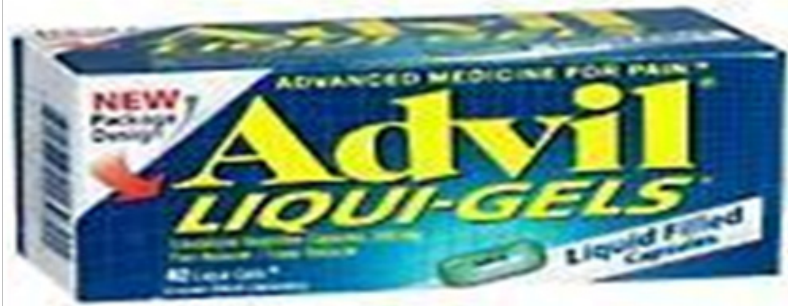

Figure $\mathbf{2}$ commercial packaging for lbuprofen (Advi) I.

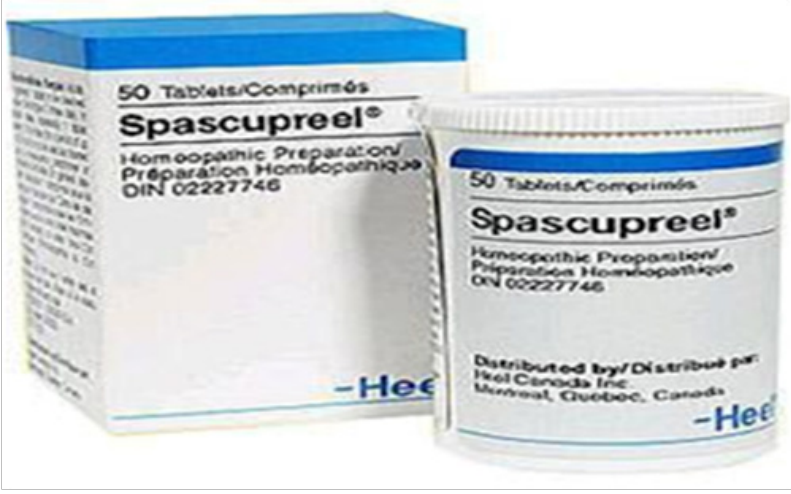

Figure 3 commercial packaging for Spascupreel.

\section{Methods}

\section{Study population}

Forty-eight women (18-45years) suffering from primary dysmenorrhoea with no other diagnostic history were included.

\section{Design}

The study population was divided into two age-matched groups at random. Twenty- four women were treated with oral soft-gel capsule $\mathrm{Advi}^{\circledR} 200 \mathrm{mg}$ and all the others were given Spascupreel ${ }^{\circledR} 300 \mathrm{mg}$ 
sublingual tablets. The course of the treatment was set for 5 days starting 24hours before the menstrual cycle. Spascupreel ${ }^{\mathbb{}}$ and Advi ${ }^{\circledR}$ were taken 3 times per day (every 8hours).

\section{Measurements/assessment}

Efficacy of each remedy was measured by assessing the effect of each treatment on dysmenorrhoea -intensity using a $100-\mathrm{mm}$ visual analogue scale (VAS), scored in a daily diary four times a day $(6 \mathrm{am}, 12 \mathrm{am}, 6 \mathrm{pm}, 12 \mathrm{pm})$. The onset of the treatment effect, global assessment of treatment, and impact of treatment on quality of everyday performance were also evaluated using scale 0-3 (3: good; 2: not bad; 1 : poor; 0 : very bad).

\section{Results}

No statistical significant difference $(\mathrm{P}>0.05)$ was found in any measurement between the two groups, although there was a difference in time course of the action. In some cases, $(60 \%)$, the onset of sublingual Spascupreel ${ }^{\circledR}$ tablets was ahead of Advi ${ }^{\circledR}$.

\section{Onset of the effect}

The onset of Sublingual Spascupree ${ }^{\circledR}$ tablets in pain relief was ahead of Advi®.

\section{Study safety}

No adverse effect was observed in either group.

\section{Statistical power}

Alpha-level and beta-level were chosen as 0.05 (type I error) and 0.20 (type II error) respectively. The study power then is 1-beta $=1$ $0.20=0.80$ or $80 \%$.

\section{Conclusion}

We concluded that Spascupreel ${ }^{\circledR}$ is comparable to $\mathrm{Advi}^{\circledR}$ with regard to pain relief, tolerability and enhancing the quality of life. Considering the well known side effects of NSAIDs e.g. Advi ${ }^{\circledR}$, it is then valuable to suggest the Spascupree ${ }^{\circledR}$ as an alternative with a safer profile for primary dysmenorrhoea.

\section{Acknowledgements}

Thanks to Macri Wellness Center, 3244 E. Guadalupe Rd, Ste. 105, Gilbert Arizona 85234 for patient recruitments and financial support.

\section{Conflicts of interest}

Author declares there no conflicts of interest.

\section{Funding}

None.

\section{References}

1. Ylikorkala O, Dawood MY. New concepts in dysmenorrhoea. Am J Obstet Gynecol. 1978;130(7):833-847.

2. Burnett MA, Antao V, Black A, et al. Prevalence of primary dysmenorrhoea in Canada. J Obstet Gynaecol Can. 2005;27(8):765770

3. Dawood MY. Dysmenorrhoea. Infertil Reprod Med Clin N Am. 1995;6:363-377.

4. Akerlund M. Pathophysiology of dysmenorrhoea. Acta Obstet Gynecol Scand suppl. 1979;87:27-32.

5. Brouard R, Bossmar T, Fournie Lloret D, et al.Effect of SR49059, an orally active V1a vasopressin receptor antagonist, in the prevention of dysmenorrhoea. BJOG. 2000;107(5):614-619.

6. Dawood MY.Hormones, prostaglandin and dysmenorrhoea. In: Dawood MY, Editor. Dysmenorrhoea. Baltimore, Maryland: Williams and Wilkins; 1981.p. 20-52.

7. Marjoribanks J, Proctor ML, Farquhar C. Nonsteroidal antiinflammatory drugs for primary dysmenorrhoea. Cochrane Database Syst Rev. 2003;(4):CD001751.

8. Ekstrom P, Akerlund M, Forsling M, et al. Stimulation of vasopressin release in women with primary dysmenorrhoea and after oral contraceptive treatment: effect on uterine contractility. $\mathrm{Br} \mathrm{J}$ Obstet Gynaecol. 1992;99(8):680-684.

9. Association of Reproductive health professionals. Choosing a Birth Control Method. Quick Reference Guide for Clinicians, Washington, USA. 2014.

10. Satu Suhonen, Maija Haukkamaa, Tell Jakobsson, et al. Clinical performance of a levonorgestrel-releasing intrauterine system and oral contraceptives in young nulliparous women: a comparative study. 2004;69(5):407-412.

11. http://endometriosis.org/treatments/gnrh/

12. Dalene Barton-Schuster, $\mathrm{CH}$, Doula. Natural Remedies for Painful Menstruation. Natural Fertility Info. 2011.

13. Find a Vitamin or Supplement.

14. Dawood MY. Multi center, randomized double-blind, crossover study comparing ketoprofen $12.5 \mathrm{mg}$ and $2 \mathrm{mg}$, ibuprofen $200 \mathrm{mg}$ and placebo in the treatment of primary dysmenorrhoea. Miles Medical Research Report No. 124. 1994.

15. Michael Weiser, Valérie Reus. Treating Spasmodic Conditions with Spascupreel. International Journal for Biomedical Research and Therapy. 2000;29(1):14-17. 